\title{
Los juicios paralelos en España: El efecto adverso de la libertad de información en la publicidad mediata
}

\author{
Parallel trials in Spain: The adverse effect of freedom \\ of information on the principle of publicity
}

\section{Cristina San Miguel Caso ${ }^{1}$}

Universidad de Cantabria, España sanmiguelc@unican.es

http://orcid.org/0000-0003-3078-6182

RESUMEN: La metodología informativa de los medios de comunicación ha experimentado una evolución notable motivada por el impacto de las nuevas tecnologías en el sector de la comunicación. Esto ha propiciado que la cobertura informativa sobre los asuntos judiciales se intensifique hasta generar el fenómeno mediático de los denominados juicios paralelos. Así, nos encontramos ante un fenómeno de carácter extrajudicial que tiene la entidad suficiente para producir serias injerencias dentro de un proceso penal. El objetivo de este trabajo es analizar, desde la perspectiva procesal, la incidencia de los juicios paralelos en relación con el principio de publicidad examinando, posteriormente, el papel que desempeñan las oficinas de comunicación del Poder Judicial español en la transmisión y difusión de la información judicial como una de las eventuales soluciones para paliar, eventualmente, los efectos perniciosos de los juicios paralelos en el proceso. Con esta finalidad pretendemos dar respuesta a varios interrogantes: ¿Es la justicia mediática el efecto adverso del inadecuado ejercicio de las libertades informativas? ¿Se ha producido una inversión en el principio de publicidad para el sujeto investigado? ¿Son las oficinas de comunicación una solución a los juicios paralelos?

Palabras-clave: Juicios paralelos; principio de publicidad; información judicial; oficinas de comunicación; proceso penal.

1 Doctora en Derecho. Profesora Ayudante de Derecho Procesal en la Universidad de Cantabria, España. 
ABSTRACT: The informative methodology of the media has undergone a remarkable evolution caused by the impact of new technologies in the communication sector. This has led to an intensification of the coverage of information on judicial issues generating the media phenomenon of the socalled parallel trials. Thereby, we face an extrajudicial nature phenomenon that is significant enough to produce serious interference in a criminal process. The objective of this work is to analyze the incidence of parallel trials in relation to the principle of publicity from the procedural perspective, examining, subsequently, the role played by the communication offices of the Judiciary of Spain in the transmission and dissemination of judicial information as one of the possible solutions to mitigate, eventually, the pernicious effects of parallel trials in the process. To this end, we intend to answer several questions: Is media justice the adverse effect of the inadequate exercise of informational freedoms? Has a reversal in the principle of publicity for the investigated subject been produced? Are communication offices a solution to parallel trials?

KeYwords: Parallel trials; principle of publicity; judicial information; communication offices; criminal process.

SUMARIO: Introducción. 1. En torno a la justicia mediática: los juicios paralelos. 1.1. La verdad noticiada y la verdad procesal. 2. Del principio de publicidad procesal al principio de publicación de los medios periodísticos. 3. La información judicial en el proceso penal español: las oficinas de comunicación. 3.1. ¿Qué información se puede facilitar durante el proceso? 3.1.1. Fase de instrucción. 3.1.2. Fase de juicio oral. 3.2. Nuevos retos para las oficinas de comunicación. Conclusiones. Bibliografía.

\section{INTRODUCCIÓN}

En la actualidad, los medios de comunicación desempeñan una función informativa esencial, actuando como los intermediarios naturales ${ }^{2}$ entre la Administración de Justicia y el ciudadano, cuando los procedimientos judiciales presentan un indudable interés informativo.

2 Tal y como indica la STC 30/1982, de 1 de junio, FJ $4^{\circ}$. 
Dicho interés deviene de multitud de factores muy diversos que se manifiestan en el contenido esencial del derecho a la información, legitimando, de esta forma, el ejercicio de las libertades informativas sobre cuestiones relativas a la Administración de Justicia ${ }^{3}$.

En este sentido, la labor de los medios de comunicación ha ido adquiriendo, de forma progresiva, un papel fundamental en la formación de la opinión pública ${ }^{4} \mathrm{y}$, consecuentemente, en la imagen y confianza que la sociedad tiene en la Justicia. El conflicto se produce cuando la información proporcionada contiene una serie de elementos que provocan una disociación entre la realidad judicial y la realidad informada que se proyecta en los diversos medios de comunicación social, existiendo, en consecuencia, un gran consenso en el parecer de jueces y magistrados que opinan ${ }^{5}$, en un $91 \%$ de los casos, que los medios de comunicación no reflejan con objetividad el quehacer judicial.

Es evidente que la publicación de hipótesis y suposiciones en los medios de comunicación es una simple consecuencia de la libertad de prensa que constituye, tal y como indicó el Tribunal Supremo español, la divisa de toda sociedad democrática ${ }^{6}$. No obstante, el problema es patente y persistente cuando la cobertura informativa sobre los asuntos judiciales puede hacer aparecer como culpables, ante la sociedad, a personas que

3 En torno a la relación entre el derecho a la información y la justicia penal resulta interesante la reflexión realizada por HUERTAS MARTÍN, Isabel. Proceso penal y comunicación en el siglo XXI: el inevitable juicio paralelo, el prescindible juicio paralelo show. En: RODRÍGUEZ GARCÍA, Nicolás; CARRIZO GONZÁLEZ-CASTELL, Adán; LETURIA INFANTE, Francisco Javier (Dirs.) Justicia penal pública y medios de comunicación, Valencia: Tirant lo Blanch, 2018, p. 429 y ss.

4 Sobre esta cuestión CAMARA NERY, Arianne. Considerações sobre o papel da mídia no processo penal. Trabalho de fim de curso - Pontifícia Universidade Católica Do Rio de Janeiro, Rio de Janeiro, 2010.

5 Dato obtenido de la VI Encuesta a la carrera judicial elaborada por Sigmados (Encuesta de ámbito nacional a todos los jueces o magistrados en servicio activo 2015). Disponible en: http://www.poderjudicial.es/cgpj/es/Poder-Judicial/Consejo-General-del-Poder-Judicial/Actividad-del-CGPJ/Encuestas/ Encuestas-a-la-Carrera-Judicial/VI-Encuesta-a-la-Carrera-Judicial--Encuesta-de-ambito-nacional-a-todos-los-jueces-o-magistrados-en-servicio-activo--2015-. Acceso en: 09/07/2020.

6 Así lo establece la STS 854/2010, de 29 de septiembre. 
solo están o han sido investigadas y que, como tal, tienen a su favor una serie de garantías procesales que, eventualmente, pueden ser quebrantadas a través de los denominados "juicios paralelos".

Nos encontramos, por lo tanto, ante una problemática de carácter extrajudicial cuyas consecuencias generan graves repercusiones en el ámbito procesal, las cuales, se ven notablemente agraviadas al tratarse de un fenómeno carente de regulación en España que, durante varias décadas, ha sido advertido tanto por la jurisprudencia como por la doctrina jurídica. Por ello, el planteamiento de la cuestión desde la perspectiva del principio de publicidad procesal se hace necesaria e imprescindible atendiendo a las vicisitudes que los juicios paralelos generan en torno al mismo.

En el presente artículo nos proponemos analizar la proyección del principio de publicidad como garantía procesal y la inversión de dicho principio como consecuencia del inadecuado ejercicio de la libertad de prensa, centrando nuestra atención en las oficinas de comunicación de la Administración de Justicia como una de las soluciones que, partiendo de la propia institución, tienen la capacidad y entidad suficiente para paliar los efectos perniciosos derivados de la publicidad mediata, entendiendo por esta la posibilidad de que la colectividad pueda tener acceso al proceso penal, no de forma directa, sino a través de la labor informativa desempeñada por el medio de comunicación?

Para la consecución de tal fin nos planteamos una serie de preguntas a las que pretendemos dar respuesta: ${ }_{i}$ Es la justicia mediática una consecuencia adversa del inadecuado ejercicio de la libertad de información? ¿Se produce una inversión del principio de publicidad? ¿Qué información se puede difundir por los medios de comunicación en cada fase del proceso? Y, por último, ¿̇son las oficinas de comunicación una solución?

7 En torno a la publicidad mediata CAMARENA ALIAGA, Gerson W. Medios de comunicación y poder judicial. Tratamiento penal y procesal frente a los juicios paralelos. Cizur Menor: Aranzadi, 2018, p. 184 y ss. 


\section{EN TORNO A LA JUSTICIA MEDIÁTICA: LOS JUICIOS PARALELOS.}

Los juicios paralelos se desenvuelven en un marco general que engloba todas aquellas informaciones tendenciosas y fragmentadas ${ }^{8}$ que carecen del requisito de la veracidad informativa y que se encuentran orientadas a crear estados de opinión en el receptor de la noticia. De esta forma y aunque la información facilitada tenga, al menos, un origen jurídico, el fenómeno se desarrolla de forma paralela al ámbito judicial ${ }^{9}$, en una sede que no le es propia ${ }^{10}$, originándose, así, la justicia mediática como el resultado inevitable del proceso o juicio paralelo iniciado por el medio de comunicación.

En torno a la aproximación conceptual de este fenómeno, es oportuno aclarar que nos encontramos ante un concepto evolutivo y en constante cambio, motivado, entre otras razones, por la irrupción de las nuevas tecnologías en el ámbito comunicacional, lo que ha supuesto una importante transformación no solo en la metodología informativa, sino también en el impacto y extensión de los juicios paralelos.

En relación con lo señalado, Leturia Infante pone de manifiesto que no existe un consenso sobre el contenido esencial de los juicios paralelos, afirmando que dicha figura "podría vincularse al seguimiento publicitado de un hecho aparentemente delictivo, realizado por la prensa

8 Como indica CARRETERO SAN JUAN, Maite; CORTÉS BECHIARELLI, Emilio. Juicios paralelos: el conflicto entre el poder judicial y los medios de comunicación en el proceso penal. Diario La Ley, n. 8902, p. 1-18, 2017; la información que conforma el juicio paralelo es sesgada, fragmentada y fuera de contexto, sustituyéndose la información por especulación.

9 Para un análisis general del fenómeno de los juicios paralelos puede consultarse las siguientes referencias: LÓPEZ GUERRA, Luis. Juicios paralelos, presunción de inocencia y jurisprudencia del Tribunal Europeo de Derechos Humanos. Teoría y derecho: revista de pensamiento jurídico, Valencia, n. 24, p. 34-49, 2018; CARRILLO, Marc. Derechos fundamentales y poder judicial en la sentencia de la manada. Teoría y derecho: revista de pensamiento jurídico, Valencia, n. 24, p. 64-91, 2018; FERNÁNDEZ GARCÍA, Emilio. Juicios paralelos, imparcialidad de los tribunales y opinión pública: repercusiones en la vida política y en las resoluciones judiciales. Teoría y derecho: revista de pensamiento jurídico, Valencia, n. 24, p. 211-219, 2018.

10 Sobre la perversión de la función informativa/formativa LATORRE LATORRE, Virgilio. Función jurisdiccional y juicios paralelos, Madrid: Civitas, 2002, p. 108 y 109. 
al margen del cauce institucional"11. En sentido contrario se manifiestan Droguett González y Walker Silva al afirmar que los juicios paralelos son legales y necesarios como resultado del correcto ejercicio de las libertades informativas $^{12}$. Esta aseveración, a nuestro juicio, debe ser matizada, ya que, a pesar de desempeñar una función esencial dentro de una sociedad democrática, la labor comunicacional debe estar, en todo caso, sujeta a unos parámetros éticos o deontológicos, propios de la profesión, cuyo cumplimiento no daría lugar a la problemática que está siendo objeto de estudio en este trabajo. No obstante, la realidad es bien distinta y como resultado de dicha omisión la cobertura informativa referente a un conflicto jurídico contendrá todos los elementos pertinentes para originar el fenómeno citado.

En este aspecto, podemos definir los juicios paralelos como aquellos procesos mediáticos, de carácter inquisitivo y sin garantías, sustentados en medios de investigación tendencialmente incriminatorios y con efectos peyorativos para la presunción de inocencia, los cuales son obtenidos frecuentemente de modo ilícito o irregular, vulnerando los derechos fundamentales y garantías procesales de las partes ${ }^{13}$.

Así, los juicios paralelos no se deben configurar como el resultado de la libertad de información, sino como el paradigma del inadecuado ejercicio de las libertades informativas ${ }^{14}$, generando una clara distorsión

11 Como indica LETURIA INFANTE, Francisco Javier. La problemática de los juicios paralelos en la jurisprudencia y doctrina española. Revista Ius et Praxis, Chile, n. 2, p. 23, 2017.

12 DROGUETT GONZÁLEZ, Carmen y WALKER SILVA, Nathalie. El derecho a ser informado sobre los asuntos de interés público: defensa de los juicios paralelos en Chile: Problemas y soluciones. Revista Chilena de Derecho, Chile, v. 47, n. 1, p. 32 y ss, 2020.

13 SAN MIGUEL CASO, Cristina. La cobertura mediática en el sistema de la estrategia de la defensa penal. En: RODRÍGUEZ GARCÍA, Nicolás; CARRIZO GONZÁLEZ-CASTELL, Adán; LETURIA INFANTE, Francisco Javier (Dirs.) Justicia penal pública y medios de comunicación, Valencia: Tirant lo Blanch, 2018, p. 372.

14 Siguiendo a ORENES RUIZ, Juan Carlos. Juicios paralelos y prensa digital. En: GAVARA DE CARA, Juan Carlos; DE MIGUEL BÁRCENA, Josu; RAGONE, Sabrina (Dir./Coord.). El control de los cibermedios. Barcelona: Bosch Editor, 2014, p. 91. 
para el proceso penal ${ }^{15}$ que alimenta a una opinión pública insatisfecha con el funcionamiento de la Administración de Justicia y de la que progresivamente se ha ido generando una peligrosa y alarmante justicia del pueblo que, para Quintero Olivares, "es diferente de la justicia de los juristas y ni siquiera coincide con el objetivo de alcanzar la verdad"16. El juicio paralelo tiene, en palabras de Cortés Bechiarelli, "escaso agrado por lo jurídico, y supone la confluencia de un buen número de intereses que no entroncan, por más que se quiera, con el fundamento de la labor jurisdiccional de un Estado de Derecho" ${ }^{17}$.

\section{1.- LA VERDAD PROCESAL Y LA VERDAD NOTICIADA}

La finalidad de estos procesos paralelos debe ser analizada desde una doble perspectiva: por un lado, debemos atender a la rentabilidad económica que busca lograr el medio de comunicación a través de la cobertura informativa sobre el asunto judicial, y, por otro, se debe poner el acento en la creación de estados de opinión en el receptor de la noticia que, mediante la verdad noticiada, asume una realidad judicial paralela y sin garantías.

Es importante, llegados a este punto, realizar una somera distinción entre la verdad noticiada y la verdad procesal por el impacto que lo transmitido tiene, como verdad noticiada, en el receptor de la información, pues la formación del juicio paralelo no solo traerá consecuencias negativas para el sujeto investigado, sino también, para la Administración de Justicia en su conjunto.

Al respecto, los juicios paralelos menoscaban la imagen de nuestro sistema judicial minando la confianza de los ciudadanos en la institución, generando una expectativa de sentencia y originando una

15 Como establece OTERO GONZALEZ, María del Pilar. Protección penal del secreto sumarial y juicios paralelos, Madrid: Centro de estudios Ramón Areces, 1999, p. 32.

16 En palabras de QUINTERO OLIVARES, Gonzalo. La justicia penal, Elcano: Aranzadi, 1998, p. 32.

17 Como indica CORTÉS BECHIARELLI, Emilio. Juicios paralelos y derechos fundamentales del justiciable. Anuario de la Facultad de Derecho. Universidad de Extremadura, Cáceres, n. XXI, p. 126, 2003. 
errónea concepción del proceso que se está llevando a cabo a través de la verdad noticiada, la cual, puede definirse como "aquellos hechos que, por estimarse noticiables, o si se prefiere, por ser de actualidad, se publican en los medios de comunicación tanto gráficos como audiovisuales ${ }^{18 ”}$. Al respecto, la información puede tener un origen ilegitimo o ser obtenida sin las garantías adecuadas, lo cual, se materializará en la inexistencia de la debida diligencia del informador.

En consecuencia, la verdad noticiada no es sinónimo de veracidad informativa, pues si bien es cierto que ambas se desarrollan en el mismo ámbito y por los mismos actores, la veracidad de la información requerirá, con carácter previo a la difusión de la información, la diligencia debida del informador. Por el contrario, la verdad noticiada se corresponde con aquella información que, sin contrastar y de manera fragmentada y descontextualizada, dibuja la realidad judicial en base a unos intereses previos.

Desde la perspectiva jurídica, la verdad procesal se construye "a través de una investigación consistente en recabar medios de prueba con total sometimiento a las normas procesales previstas tanto en la Constitución como en la Ley de Enjuiciamiento Criminal"19. En virtud de lo indicado, se ha manifestado el Tribunal Constitucional al estimar que "la búsqueda de la verdad, incluso suponiendo que se alcance, no justifica el empleo de cualquier medio, ya que la verdad no puede alcanzarse a cualquier precio. La justicia obtenida a cualquier precio termina no siendo justicia" ${ }^{20}$.

Sobre este extremo, es imprescindible resaltar el tratamiento que realiza Wach sobre la verdad en el proceso, al mantener que "la comprobación de la verdad no es la finalidad del proceso civil y no puede

18 En palabras de RODRÍGUEZ RAMOS, Luis. La verdad y las verdades en el proceso penal. ¿Hacia una justicia dependiente de los medios de comunicación?. La Ley: Revista jurídica española de doctrina, jurisprudencia y bibliografía, Madrid, n. 5, p. 1506 - 1512, 2002.

19 El citado autor RODRÍGUEZ RAMOS, Luis. La verdad y las verdades en el proceso penal ¿Hacia una justicia dependiente de los medios de comunicación? La Ley: Revista jurídica española de doctrina, jurisprudencia y bibliografía, Madrid, n. 5, p. 1506 - 1512, 2002.

STS $79 / 2012$, de 9 de febrero, FJ $7.2^{\circ}$ y $11.6^{\circ}$. 
serlo. Esa comprobación es un resultado contingente. La verdad material solo es imaginable como finalidad del proceso, en un procedimiento oficial, esto es, en un proceso que no solo da margen a una reconstrucción completa de la situación de hecho, sino que establece la máxima de la libre investigación como un deber oficial de los órganos del Estado. Y ello solo puede suceder cuando el objeto del proceso es de interés público. En el proceso civil la naturaleza jurídico-privada de ese objeto elimina la máxima de la 'libre investigación' y, con esto, la finalidad del proceso consiste en la comprobación objetiva del verdadero estado de cosas"21.

Tradicionalmente, la verdad procesal ha sido tratada por nuestro Tribunal Constitucional en relación con la veracidad informativa, al establecer que "no es constitucionalmente aceptable estimar que los informadores incumplieron el deber de diligencia en el desempeño de su labor, con apoyo exclusivo en el solo dato de que el resultado final de las investigaciones llevadas a cabo en el proceso penal fuera distinto al expuesto o transmitido por los autores de la noticia, pues la veracidad de la información difundida acerca de los hechos objeto de investigación penal no puede equipararse con la correlación entre aquella y la verdad procesal alcanzada conclusiva o finalmente en la causa penal"22.

En virtud de lo indicado, la veracidad informativa no puede equipararse a la verdad procesal, ya que ello significaría asimilar la veracidad de la información con el resultado alcanzado en el proceso penal, lo que, sin duda alguna, generaría graves inseguridades jurídicas en los conflictos planteados en torno a la veracidad informativa. En consecuencia, podemos concluir que, la verdad noticiada, tampoco, debe equipararse, en modo alguno, a la verdad procesal. De hecho, ambas son contrarias y representan una clara antítesis.

Mientras que la verdad procesal se obtiene dentro de una serie de garantías que implican alcanzar la verdad solo a través de medios legítimos y constitucionales, la verdad noticiada se caracteriza por elaborarse sin ningún tipo de garantías para el receptor de la noticia, que, recibirá de

21 Sobre el tratamiento de la verdad en el proceso, resulta fundamental el estudio y las digresiones que realiza WACH, Adolf. Conferencias sobre la ordenanza procesal civil alemana (Trad. E. Krotoschin), Buenos Aires: Ediciones Jurídicas Europa-América, 1958, p. 224 y ss. STC 158/2003, de 15 de septiembre, FJ $6^{\circ}$. 
forma errónea la verdad noticiada como si de la verdad procesal se tratase, siendo este el principal problema de la confrontación entre ambas.

La falta de correspondencia entre la verdad noticiada y la verdad procesal obedece, en términos jurisprudenciales, al igual que en el caso de la veracidad, a una cuestión de seguridad y lógica jurídica. No obstante, "ambas verdades se interfieren recíprocamente, generando en ocasiones perversos sinergismos que llegan a convertir en principal, el proceso mediático por tener en esta sociedad más relevancia la apariencia que la realidad"23.

Así, la elaboración de una noticia constituye, por lo general, el resultado de una reconstrucción o interpretación de hechos reales ${ }^{24}$ en la que intervienen distintos factores que pueden conducir a versiones dispares sobre una misma realidad ${ }^{25}$. Por esta razón, uno de los efectos que, consecuentemente, produce la verdad noticiada es la confusión en el receptor de la información que equipara lo recibido a la verdad obtenida en el proceso en un nuevo escenario de posverdad ${ }^{26}$.

Por otro lado, la reiteración de esta conducta generaría la distorsión del proceso judicial ${ }^{27}$ y la creación de un juicio paralelo, ya que la información que origina un proceso mediático de carácter

23 Como establece RODRÍGUEZ RAMOS, Luis. La verdad y las verdades en el proceso penal ¿Hacia una justicia dependiente de los medios de comunicación?. La Ley: Revista jurídica española de doctrina, jurisprudencia y bibliografía, Madrid, n. 5, p. 1506 - 1512, 2002.

STC $297 / 2000$, de 11 de diciembre, FJ $10^{\circ}$.

25 STC 99/2011, de 20 de junio, FJ $5^{\circ}$.

26 Tal y como lo califica BUENO DE MATA, Federico. El principio de publicidad procesal ante la tecnología: juicios mediáticos, redes sociales y big data. En: RODRÍGUEZ GARCÍA, Nicolás; CARRIZO GONZÁLEZ-CASTELL, Adán; LETURIA INFANTE, Francisco Javier. (Dirs.). Justicia penal pública y medios de comunicación, Valencia: Tirant lo Blanch, 2018, p. 480 y ss.

En torno a esta cuestión GUZMÁN FLUJA, Vicente Carlos. Juicios paralelos en las redes sociales y proceso penal. IDP: revista de internet, derecho y política. n. 27, p. 54, 2018. https://doi.org/10.7238/idp.v0i27.3148. sostiene que "lo que puede y debe hacerse es establecer las reglas que impidan que el juicio paralelo mediático, así como los estados de opinión pública que producen, llegue a influir en el juicio penal, así como garantizar que la libertad de información se ejerce conforme a las reglas éticas de respeto a lo que sucede en el juicio oral, sin tergiversarlo, sin distorsionarlo, sin adelantar conclusiones a partir de los datos que van apareciendo". 
extrajudicial no es la información veraz, sino aquella información fragmentada, descontextualizada y orientada a la satisfacción de unos intereses concretos, ajenos a la Administración de Justicia, que conforman la denominada verdad noticiada.

\section{DEL PRINCIPIO DE PUBLICIDAD PROCESAL AL PRINCIPIO DE PUBLICACIÓN DE LOS MEDIOS PERIODÍSTICOS}

El principio de publicidad procesal representa, en la actualidad, un pilar fundamental en la concepción moderna de la justicia penal, siendo una de las contribuciones más meritorias del pensamiento ilustrado ${ }^{28}$. La implantación de este principio en el ordenamiento jurídico tenía como objetivo reformular la concepción de la justicia propia del Antiguo Régimen ${ }^{29}$ y orientar el nuevo sistema procesal hacia una justicia transparente, más participativa y, a todas luces, más justa.

Por esta razón, la publicidad en el proceso se formuló, desde sus orígenes, como un mecanismo de control sobre la actividad jurisdiccional en la que la labor de jueces y magistrados se encontraba sometida al control ciudadano ${ }^{30}$. En la línea indicada, Couture señaló la importancia de este principio definiéndolo como "el instrumento de fiscalización popular sobre la obra de magistrados y defensores", afirmando que, en este sentido, "el pueblo es el juez de los jueces"31.

${ }^{28}$ Sobre el origen del principio de publicidad puede consultarse WYNESS MILLAR, Robert. Los principios formativos del procedimiento civil (Trad. C. Grossmann), Buenos Aires: Ediar S.A. Editores, 1945, p. 185 y ss; y para realizar un estudio más profundo sobre el movimiento reformista del siglo XVIII, RENEDO ARENAL, María Amparo. Problemas del imputado en el proceso penal, Madrid: Editorial Universitaria Ramón Areces, 2007, p. 69 y ss.

PEDRAZ PENALVA, Ernesto. Publicidad y derecho al debido proceso. Publicidad y derecho de acceso a la información contenida en los ficheros de datos jurisdiccionales. En: GUTIÉRREZ-ALVIZ CONRADI, Faustino. (Dir.), Criminalidad organizada ante la justicia, Sevilla: Universidad de Sevilla, 1996, p. 161.

30 Siguiendo a ASENCIO MELLADO, Jose María. El proceso penal con todas las garantías. Revista Ius et veritas, Lima, n. 33, p. 239, 2006.

31 COUTURE, Eduardo. Fundamentos del Derecho Procesal Civil, Buenos Aires: Depalma, 1990, p. 192 y 193. 
No obstante, para la consecución de esta labor fiscalizadora sobre la actividad jurisdiccional es preciso que el principio de publicidad logre su máximo alcance superando las barreras impuestas por la publicidad inmediata. Así, el Tribunal Constitucional español ha manifestado, en varias de sus sentencias, la necesidad de que el principio de publicidad se proyecte sobre la generalidad de un público, más allá, de las limitaciones físicas o de espacio que implica la sala de vistas, argumentando que "el principio de la publicidad de los juicios, garantizado por la Constitución (art. 120.1), implica que estos sean conocidos más allá del círculo de los presentes, pudiendo tener una proyección general. Esta proyección no puede hacerse efectiva más que con la asistencia de los medios de comunicación social, en cuanto tal presencia les permite adquirir la información en su misma fuente y transmitirla a cuantos, por una serie de imperativos de espacio, de tiempo, de distancia, de quehacer, etc., están en la imposibilidad de hacerlo. Este papel de intermediario natural desempeñado por los medios de comunicación social entre la noticia y cuantos no están, así, en condiciones de conocerla directamente, se acrecienta con respecto a acontecimientos que por su entidad pueden afectar a todos y por ello alcanzan una especial resonancia en el cuerpo social"32.

De esta forma, la presencia de los medios de comunicación en la sala de vistas es necesaria para satisfacer los objetivos de este principio, pudiendo afirmar, en consecuencia, que la proyección general del principio de publicidad se alcanza a través de la denominada publicidad mediata ${ }^{33}$. Así, el Tribunal Constitucional ha reconocido un derecho preferente a los medios de comunicación en virtud de la función informativa que tienen atribuida, sin que el mismo pueda entenderse como un privilegio discrecional para aquellos.

Sobre esta cuestión se ha manifestado Montero Aroca considerando que la publicidad debe acomodarse a los tiempos, y, por ello, no se puede desatender a los medios de comunicación social por la función que desempeñan. En opinión del citado autor "el proceso público es aquel al que pueden tener acceso los medios de comunicación que se constituyen

\footnotetext{
32 Así se establece en la STC 30/1982, de 1 de junio, FJ $4^{\circ}$.

33 LATORRE LATORRE, Virgilio. Función jurisdiccional y juicios paralelos, Madrid: Civitas, 2002 p. 108.
} 
como una especie de representantes del público y como tales, tienen sus mismos derechos, pero no más" 34 .

En torno al principio de publicidad, es preciso destacar la evolución que, dicho principio, ha experimentado con el paso del tiempo ${ }^{35}$, transformación que se ha llevado a cabo, entre otros factores, por la difusión y creciente mecanización de los medios de comunicación social, pasando así, de una publicidad inmediata a una publicidad mediata que acerca el funcionamiento de la justicia a toda la población, reforzando el control de estos sobre la actividad judicial.

Desde la perspectiva que nos ocupa, podemos definir la publicidad mediata como una vertiente del principio de publicidad procesal que se encuentra conformada por la información judicial suministrada por los medios de comunicación que actúan como intermediarios naturales entre la Administración de Justicia y los ciudadanos, sin la necesidad de la presencia física de estos en la sala de vistas.

Sin embargo, es conveniente matizar que, la relación que se genera entre los medios de comunicación y los ciudadanos, en torno a la publicidad mediata no está exenta de controversia, constatándose, como ha señalado el Tribunal Supremo, "un distorsionado entendimiento del principio de publicidad procesal, garantía procesal del constitucionalismo liberal que está siendo reemplazada, con mucha más frecuencia de lo tolerable, por una publicación del proceso"36.

Esta afirmación invita a reflexionar sobre la inversión que el principio de publicidad ${ }^{37}$ ha experimentado, en virtud de la dimensión

34 Vid. MONTERO AROCA, Juan; GÓMEZ COLOMER, Juan Luis; MONTÓN REDONDO, Alberto; BARONA VILAR, Silvia. Derecho jurisdiccional I, Valencia: Tirant lo Blanch, 2008, p. 400.

35 Al respecto puede consultarse la reflexión realizada por NIEVA FENOLL, Jordi. Los juicios paralelos: su complejo encaje constitucional. En: MIR PUIG, Santiago; CORCOY BIDASOLO, Mirentxu (Dir.), Protección penal de la libertad de expresión e información: Una interpretación constitucional, Valencia: Tirant lo Blanch, 2012, p. 224.

36 STS 14/2018, de 16 de enero.

37 Aspecto señalado por PERAL PARRADO, María. La presunción de inocencia y la defensa efectiva: la responsabilidad de los medios y de los periodistas. Revista del Consejo General de la Abogacía Española, Madrid, n.111, p. 28, 2018. 
social adquirida por el asunto judicial pues, lo que originariamente era un derecho del justiciable, en la actualidad, el principio de publicidad deja paso a un equívoco principio de publicación en el que la información proporcionada sobre el conflicto jurídico responde a unos intereses extrínsecos a la Administración de Justicia pues, como señaló Couture, "la malsana publicidad, el escándalo, la indebida vejación de aquellos que no pueden acudir a los mismos medios porque su propia dignidad se los veda, pueden no solo invalidar esa garantía sino también transformarla en un mal mayor. La prudencia debe acudir en ese punto en auxilio de la justicia”38. De esta forma, el principio de publicación del proceso debe ser entendido como la distorsión del principio de publicidad procesal que se produce como consecuencia del inapropiado ejercicio informativo de los medios de comunicación sobre los asuntos judiciales. Tal y como indicó el Tribunal Supremo en la sentencia 1394/2009, de 25 de enero: "La garantía que ofrece el principio de publicidad deja paso así a un equívoco principio de publicación, en el que todo se difunde, desde el momento mismo del inicio de las investigaciones, sin que el acusado pueda defender su inocencia. (...) No podemos olvidar, además, que en el proceso penal convergen intereses de muy diverso signo. Y no faltan casos en los que ese tratamiento informativo despliega una repercusión negativa que llega a ser igualmente intensa y alcanza a otros bienes jurídicos, recrudeciendo el daño inicialmente ocasionado por el delito"

Este planteamiento que realizamos calificando a la denominada "justicia mediática" como el efecto adverso de la publicidad mediata, debe ser sometido a examen con una serie de cautelas, pues, indudablemente, la distorsión del principio de publicidad es ocasionada por factores externos al proceso, cuya influencia puede repercutir, notablemente, en el estigma social del sujeto investigado.

Resulta conveniente considerar que el desequilibrio que produce la publicidad mediata en el fundamento original del principio de publicidad entronca con lo que podríamos denominar la pseudopublicidad judicial, ya que, en realidad, la información suministrada mediante la función informativa de los medios de comunicación puede no contener

38 Vid. COUTURE, Eduardo J. Fundamentos del Derecho Procesal Civil, Buenos Aires: Depalma, 1990, p. 192 y 193. 
las garantías constitucionales propias que la hagan verídica y objetiva y, en consecuencia, la función de los medios de comunicación en el ámbito judicial se ve empañada por la confluencia de intereses económicos y sociopolíticos que perturban el principio de publicidad de las actuaciones judiciales.

Por lo expuesto anteriormente, y ante las evidentes vicisitudes que plantea esta problemática, resulta determinante reforzar, desde la propia Administración de Justicia, la función informativa que desempeñan las oficinas de comunicación ${ }^{39}$ a lo largo de todo el proceso. Alcanzar la máxima proyección del principio de publicidad no debe recaer, exclusivamente, en actores con réditos ajenos al proceso, razón por la cual es oportuno realizar un análisis sobre el desempeño de los gabinetes de comunicación de la Administración de Justicia con el objetivo de resaltar y fortalecer su labor comunicacional frente a la ciudadanía, como una de las eventuales soluciones para evitar la publicidad pseudoinformada y, en consecuencia, la formación de nuevos juicios o procesos paralelos.

\section{LA INFORMACIÓN JUDICIAL EN EL PROCESO PENAL ESPAÑOL: LAS OFICINAS DE COMUNICACIÓN.}

La creación de las oficinas de prensa se ha producido de forma paulatina y gradual hasta establecerse, en la actualidad, un sólido y fuerte sistema de gabinetes de comunicación en la Administración de Justicia.

Hasta hace relativamente poco tiempo, en España no existía una regulación que estableciese un cauce específico y determinado para la transmisión y difusión de la información relativa a los asuntos judiciales, situación que se reproducía, igualmente, en países de nuestro entorno como Francia, Portugal e Italia ${ }^{40}$.

39 DEL RIEGO, Carmen. Frente a los juicios paralelos, información y rigor. Cuadernos de periodistas: revista de la Asociación de la Prensa de Madrid, n. 39, p. 52, 2019. Disponible en: http://www.cuadernosdeperiodistas.com/media/2020/02/42_53-Carmen-del-Riego-1.pdf. Acceso en: 17 nov.2020.

40 Sobre esta cuestión puede consultarse las líneas de FERNÁNDEZ MARTÍNEZ, Juan Manuel. El derecho a la libertad de expresión del juez, límites en consideración a su "status de especial sujeción" y en relación con las garantías procesales y derechos objeto de protección respecto a los intervinientes en el 
A nivel nacional, el origen de los gabinetes de comunicación se remonta al año 1981 con la primera oficina de prensa adscrita al Consejo General del Poder Judicial (en adelante CGPJ). No obstante, en ese mismo año, el CGPJ, en su primera memoria anual de la institución ${ }^{41}$ puso de manifiesto la urgente y acuciante necesidad de dotar de las correspondientes oficinas de prensa al Tribunal Supremo, a la Audiencia Nacional, a las Audiencias Territoriales y al Tribunal Central del Trabajo, con el objetivo de lograr una mayor transparencia informativa acorde a la difusión de una información responsable, pretensión que se concretó, cinco años más tarde, en el acuerdo del pleno del CGPJ de 5 de noviembre de $1986^{42}$.

El proceso de implantación de las oficinas de prensa se inició escalonadamente incorporando las mismas en el Tribunal Supremo y en los Tribunales Superiores de Justicia de Valencia, Cataluña, Galicia, y Extremadura. Posteriormente, en los primeros meses de 2004 se abrieron cinco Gabinetes de Comunicación, cuatro en los Tribunales Superiores de Justicia de Madrid, Castilla-La Mancha, Baleares y el País Vasco, y uno en la Audiencia Nacional ${ }^{43}$.

En el año 2004, 9 de los 17 Tribunales Superiores de Justicia ya contaban con sus correspondientes oficinas de comunicación que, en su temprana implantación, arrojaban resultados bastante positivos sobre la labor informativa correspondiente al tribunal en el que estuvieran

proceso. Los gabinetes de comunicación y su papel como cauce institucional de información. En: FRESNEDA PLAZA, Felipe (Dir.), Justicia y Medios de Comunicación, Cuadernos de Derecho Judicial, Madrid: Consejo General del Poder Judicial, n. 16, 2006, p. 199 y ss.

41 Puede consultarse la memoria del Consejo General del Poder Judicial de 1981 en ZURITA PINILLA, Agustín. Oficinas de prensa en la Administración de justicia. Revista del Poder Judicial, La Laguna, n. extra 13, p. 238 y 239, 1990.

42 Puede consultarse íntegramente el acuerdo del pleno del Consejo General del Poder Judicial en ZURITA PINILLA, Agustín. Oficinas de prensa en la Administración de justicia. Revista del Poder Judicial, La Laguna, n. extra 13, p. 239, 1990.

43 Así lo refleja el Protocolo de comunicación de la Justicia del año 2004, p. 3. Disponible en: http://www.poderjudicial.es/cgpj/es/Poder-Judicial/Tribunales-Superiores-de-Justicia/TSJ-Cataluna/Actividad-del-TSJ-Cataluna/ Protocolos-y-convenios/Protocolo-de-Comunicacion-de-la-Justicia---Aprobado-por-el-Pleno-del-7-de-julio-de-2004. Acceso en: 03/07/2020. 
adscritos. Esta circunstancia motivó que la comisión de comunicación acordara el 31 de mayo de 2004 la creación del resto de los gabinetes de comunicación, previendo que, en enero de 2005, habría gabinetes en el Tribunal Supremo, la Audiencia Nacional y en los 17 Tribunales Superiores de Justicia de las Comunidades Autónomas. Actualmente, esta previsión es una realidad.

Las razones que motivaron la formación de las oficinas de prensa pivotaron, principalmente, en el limitado acceso que tenían los periodistas a la información relevante sobre los asuntos judiciales considerados de interés público para la ciudadanía. Así, Zurita Pinilla ponía de relieve que "no parece de recibo que una importantísima parte de la producción judicial de nuestro país quede en el más puro anonimato, bien por la desidia de la Administración de Justicia, bien por la escasa preparación de los periodistas, bien por el interés de determinados medios de información de resaltar el suceso judicial y las resoluciones llamativas por el escándalo que despiertan" 4 .

Por otro lado, existía cierta preocupación cuando un juez o magistrado realizaba declaraciones públicas que pudieran, eventualmente, poner en entredicho la imparcialidad del órgano enjuiciador, ya que, como indicó Fernández Martínez, la información judicial, por la entidad de su contenido y las posibles repercusiones de su difusión, debían canalizarse a través de los gabinetes de comunicación ${ }^{45}$.

De esta forma, el citado autor sostenía que "era urgente descargar al juez del compromiso de tener que exponer públicamente los aspectos relevantes de aquello que estaba llamado a resolver y encomendarlo a alguien que, respetuoso con los valores en juego,

${ }^{44}$ Siguiendo a ZURITA PINILLA, Agustín. Oficinas de prensa en la Administración de justicia. Revista del Poder Judicial, La Laguna, n. extra 13, p. 233234, 1990.

45 En palabras de FERNÁNDEZ MARTÍNEZ, Juan Manuel. El derecho a la libertad de expresión del juez, límites en consideración a su "status de especial sujeción" y en relación con las garantías procesales y derechos objeto de protección respecto a los intervinientes en el proceso. Los gabinetes de comunicación y su papel como cauce institucional de información. En: FRESNEDA PLAZA, Felipe (Dir.), Justicia y Medios de Comunicación, Cuadernos de Derecho Judicial, Madrid: Consejo General del Poder Judicial, n. 16, 2006, p. 212. 
pudiera hacerlo ya no solo sin menoscabo de la información sino, antes, al contrario, reforzándola" ${ }^{46}$.

En línea con lo indicado, otro de los motivos que propició la creación estructural y funcional de las oficinas de comunicación fue, sin duda alguna, fortalecer y consolidar la imagen de la justicia, cuya percepción por la ciudadanía aún sigue siendo un reto para la estrategia comunicacional de la Administración de Justicia, debido, entre otras razones, a que se trata de un poder desconocido para la sociedad en su conjunto, que lo percibe como oscuro, complicado e incomprensible ${ }^{47}$.

Por lo tanto, los gabinetes de comunicación surgieron como una necesidad que pretendía dar respuesta a todas aquellas deficiencias que, en su faceta externa, se venían postergando durante décadas. Sin embargo, es conveniente aclarar que las oficinas de prensa no surgieron para ser la solución que erradicara todas las deficiencias ad extra del sistema judicial, sino para establecer un sólido sistema comunicacional en el que se garantizase la veracidad, la objetividad y la transparencia de la información derivada de un conflicto jurídico. Por esta razón compartimos la opinión de Zurita Pinilla cuando afirma que "la panacea de estos males no la tiene en exclusiva la creación de las oficinas de prensa, pero al menos, estaremos colocando las bases de una información más objetiva, por no discriminatoria y por abarcar otros campos de la actividad judicial, que andan hoy en precario, cuáles son los órdenes civiles, contenciosos y sociales. La selección de la información si podrá recaer en el periodista

46 El citado autor FERNÁNDEZ MARTÍNEZ, Juan Manuel. El derecho a la libertad de expresión del juez, límites en consideración a su "status de especial sujeción” y en relación con las garantías procesales y derechos objeto de protección respecto a los intervinientes en el proceso. Los gabinetes de comunicación y su papel como cauce institucional de información. En: FRESNEDA PLAZA, Felipe (Dir.), Justicia y Medios de Comunicación, Cuadernos de Derecho Judicial, Madrid: Consejo General del Poder Judicial, n. 16, 2006, p. 201.

47 Tal y como determina el Protocolo de Comunicación del Poder Judicial del año 2020, p. 6. Disponible en:http://www.poderjudicial.es/cgpj/es/ Poder-Judicial/Tribunal-Supremo/Oficina-de-Comunicacion/Protocolo-de-Comunicacion-de-la-Justicia/. Acceso en: 03/07/2020. 
de tribunales y, en principio, la sociedad estará en condiciones de poseer más y mejor información” ${ }^{48}$.

Los gabinetes de comunicación han logrado, con el paso del tiempo, cumplir en gran medida el objetivo de su creación, convirtiéndose en la piedra angular de la política de comunicación del CGPJ y actuando como el cauce institucional entre la Administración de Justicia y los medios de comunicación. Para ello, se han convertido en una fuente oficial y fiable de información a la que deberán acudir asiduamente los medios periodísticos para obtener todos aquellos datos judiciales que deban ser objeto de difusión y transmisión a la opinión pública. Por otro lado, asistimos a una nueva realidad impulsada por la presencia de las citadas oficinas en las redes sociales, lo que facilita e inspira un acercamiento de la institución a la sociedad a través de una comunicación más fluida entre ambos, sin ningún tipo de intermediario, pudiendo el ciudadano consultar de forma directa la fuente primaria de la información judicial.

\section{1. ¿QUÉ INFORMACIÓN SE PUEDE FACILITAR DURANTE EL PROCESO?}

Para dar respuesta a esta cuestión, las oficinas de comunicación, en el desempeño de sus funciones, deben facilitar a los medios de comunicación la información más relevante sobre aquellos asuntos jurídicos que hayan suscitado un cierto interés general ${ }^{49}$ en la opinión pública.

En este sentido, un asunto judicial se considerará de interés "cuando despierte la atención de los medios de comunicación por las personas que intervienen, el objeto del proceso, la relevancia del hecho objeto del procedimiento, la relevancia jurídica de las resoluciones dictadas y/o las normas jurídicas aplicadas, la previa existencia de informaciones

48 Tal y como indica ZURITA PINILLA, Agustín. Oficinas de prensa en la Administración de justicia. Revista del Poder Judicial, La Laguna, n. extra 13, p. 234, 1990.

49 Sobre esta cuestión GARCÍA ARÁN, Mercedes. Libertad de información y procesos penales en curso. Teoría y derecho: revista de pensamiento jurídico, Valencia, n. 24, p.18, 2018. 
periodísticas sobre el mismo, incluso en su fase policial, o se considere que es de interés para la ciudadanía" ${ }^{50}$.

La definición contenida en el párrafo anterior es sumamente significativa al establecer, de forma indirecta, la prelación sobre el interés suscitado. Es decir, un asunto se considerará de interés cuando, en primer lugar, despierte la atención de los medios de comunicación, y, en segundo lugar, se considere de interés para la ciudadanía. Coincidimos en esta singular idea, ya que, el interés que un asunto pueda despertar en la opinión pública viene predeterminado tanto por la selección de la información que decide tratar, como por la orientación, sesgo ideológico o mensaje que el medio de comunicación ${ }^{51}$ pretenda transmitir en la difusión de la información. A ello se suma, además, la imposibilidad de negar, por regla general, interés noticioso a hechos o sucesos de relevancia penal ${ }^{52}$ por lo que la información judicial que puede ser objeto de difusión alcanza, en el proceso penal, ciertas particularidades atendiendo a las distintas fases del proceso en la que nos encontremos.

\subsection{1.- FASE DE INSTRUCCIÓN}

La fase de instrucción en el proceso penal español se caracteriza por el carácter reservado de sus diligencias, de forma que el secreto sumarial ${ }^{53}$ se configura como un límite informativo en la fase inicial del proceso. No obstante, esta afirmación debe ser matizada ya que la restricción informativa opera de forma parcial, afectando, únicamente, a

50 Tal y como señala el Protocolo de comunicación del 2020, p. 8. Disponible en: http://www.poderjudicial.es/cgpj/es/Poder-Judicial/Tribunal-Supremo/Oficina-de-Comunicacion/Protocolo-de-Comunicacion-de-la-Justicia/. Acceso en: 03/07/2020.

51 LAZZARI DA SILVEIRA, Felipe. Mídia, medo e controle: Ensaio sobre o papel da mídia na dinãmica do recrudescimento do sistema penal. Cadernos de Comunicação, v.20, n.2, p.1-21, 2016.

Así lo determina la STC 178/1993, de 31 de mayo, FJ $4^{\circ}$.

53 Sobre la naturaleza jurídica del secreto sumarial puede consultarse RODRÍGUEZ BAHAMONDE, Rosa. El secreto del sumario y la libertad de información en el proceso penal, Madrid: Dykinson, 1999, p. 253. 
aquellos elementos o datos que se encuentran bajo secreto, evitando así generar reservas u obstáculos en el ejercicio de las libertades informativas ${ }^{54}$.

Por lo tanto, las oficinas de comunicación, previa autorización del juez de instrucción, podrán difundir a los medios de comunicación la información que, no teniendo un carácter reservado, sea de relevancia para la formación la opinión pública. Así, datos como la situación procesal acordada tras la toma de declaración, el número de testigos que han declarado o la identidad de los sujetos investigados pueden ser difundidos a los medios periodísticos ${ }^{55}$. Sin embargo, la previsión que realiza el Protocolo de comunicación sobre la eventual difusión de la identidad de los investigados requiere, en nuestra opinión, ser matizada, pues no clarifica, en modo alguno, la forma en la que esta información debe ser transmitida, es decir, si la identidad se puede manifestar abiertamente o si, por el contrario, dicha información está sujeta a ciertas restricciones con la finalidad de salvaguardar la presunción de inocencia y el honor del sujeto.

Se trata, por lo tanto, de modular el ejercicio de dicha labor informativa ${ }^{56}$ estableciendo el método que sea más garante para procurar,

54 Sobre esta cuestión la STC 13/1985, de 31 de enero, determinó en su FJ $3^{\circ}$ que: "El secreto del sumario no significa, en modo alguno, que uno o varios elementos de la realidad social (sucesos singulares o hechos colectivos cuyo conocimiento no resulte limitado o vedado por otro derecho fundamental según lo expuesto por el art. 20.4 de la C.E.) sean arrebatados a la libertad de información, en el doble sentido de derecho a informarse y derecho a informar, con el único argumento de que sobre aquellos elementos están en curso unas determinadas diligencias sumariales. De ese modo, el mal entendido secreto del sumario equivaldría a crear una atípica e ilegítima 'materia reservada' sobre los hechos mismos acerca de los cuales investiga y realiza la oportuna instrucción el órgano judicial, y no sobre 'las actuaciones' del órgano judicial que constituyen el sumario".

55 A estos datos se suman otros contenidos en el Protocolo de Comunicación de la Justicia del año 2020, p. 10. Disponible en: http://www.poderjudicial. es/cgpj/es/Poder-Judicial/Tribunal-Supremo/Oficina-de-Comunicacion/ Protocolo-de-Comunicacion-de-la-Justicia/. Acceso en: 05/07/2020.

56 En torno a la relación de la publicidad procesal y el derecho a la información LETURIA INFANTE, Francisco Javier. La publicidad procesal y el derecho a la información frente a asuntos judiciales. Análisis general realizado desde la doctrina y jurisprudencia española. Revista chilena de derecho, Chile, v. 45, n. 3, p. 647-673, 2018. 
por un lado, la difusión de la información, protegiendo, por otro lado, los derechos del investigado ${ }^{57}$. Se debe mostrar, sobre esta cuestión, una posición cautelosa en cuanto a la transmisión, difusión y publicación de la identidad del sujeto ante la opinión pública por las consecuencias que la revelación de esta información pudiera ocasionar en la esfera personal del sujeto.

\subsection{2.- FASE DE JUICIO ORAL}

El principio de publicidad procesal alcanza, en la fase de juicio oral, una proyección significativa, ya que, con carácter general, esta fase será pública a excepción de las limitaciones contenidas en la Ley de Enjuiciamiento Criminal cuando así lo exijan razones de seguridad y orden público, o la adecuada protección de los derechos fundamentales de los intervinientes.

En esta fase del proceso los medios de comunicación audiovisuales adquieren un mayor protagonismo frente al medio de comunicación escrito pero, a pesar de ello, no existe una norma concreta que regule el acceso de estos medios a la sala de vistas. Con la publicación del citado protocolo de comunicación se aporta una solución parcial ${ }^{58}$ a los múltiples interrogantes que se planteaban en torno al desempeño de la labor audiovisual de estos medios, de forma que se establecen unas pautas concretas y determinadas que actuarán en un doble plano: por un lado, como garantías para un desempeño más óptimo de la función informativa y, por otro, como límites

57 Sobre la relación existente entre los juicios paralelos y la vulneración de los derechos del investigado puede consultarse AMARILLO VOZMEDIANO, María de la Fe. Juicios paralelos y derechos del investigado y el encausado. La ley penal: revista de derecho penal, procesal y penitenciario, n. 142, p. 3 y ss, 2020.

58 Estas pautas contempladas en el Protocolo de Comunicación del año 2020 establecen los criterios para la grabación de imágenes de los intervinientes en la vista oral. Estos consistirán principalmente en el consentimiento previo para la grabación de los sujetos y en una serie de limitaciones para salvaguardar la imagen de testigos protegidos, víctimas o miembros del jurado. Igualmente se establecen unas reglas mínimas referentes a los periodos de grabaciones y a los planos generales autorizados. Para más información sobre este extremo puede consultarse la p. 16 en esta dirección web: http://www.poderjudicial. es/cgpj/es/Poder-Judicial/Tribunal-Supremo/Oficina-de-Comunicacion/ Protocolo-de-Comunicacion-de-la-Justicia/. Acceso en: 05/07/2020. 
que permitirán salvaguardar, en la medida de lo posible, la imagen y el honor de los intervinientes en el proceso.

\subsection{NueVos RETOS PARA LAS OfICINAS DE COMUNICACIÓN}

En la actualidad, el papel que desempeñan las oficinas de prensa reviste una especial y merecida consideración en el ámbito informativo. No obstante, es preciso señalar que las perspectivas de futuro obligan a las mismas a seguir trabajando de forma unánime y constante en aras a la plena consecución de los nuevos retos que se presentan.

Indudablemente, el primer desafío al que se enfrentarán estas oficinas consistirá en seguir elaborando estrategias de comunicación que se centren en mejorar y reforzar la imagen que los ciudadanos tienen de la Justicia y, en consecuencia, propiciar un aumento de la confianza de la ciudadanía en la institución. Este reto, perenne desde su creación, deberá guiar las políticas de comunicación que se adopten en un futuro. Sin embargo, es necesario dar un paso más y profundizar en los motivos que originan una imagen distorsionada de la Justicia en España.

Es evidente que gran parte de esa distorsión se ha debido a la tergiversación informativa de la que, en numerosas ocasiones, hemos sido receptores. Las informaciones tendenciosas orientadas a intereses particulares o económicos han ido confeccionando una panorámica disoluta en donde la Administración de Justicia y el papel desempeñado por sus operadores ha sido criticado y cuestionado en numerosas ocasiones ${ }^{59}$.

De hecho, el progresivo empeoramiento en la concepción que la ciudadanía tiene de la Administración de Justicia se ha puesto de manifiesto en los distintos barómetros de opinión ${ }^{60}$ que, año tras año, han

59 Sobre esta cuestión es interesante la puntualización realizada en el Protocolo de comunicación del Poder Judicial en el que se manifiesta que "la gran mayoría de los ciudadanos no tienen a lo largo de su vida contacto con la Administración de Justicia, por lo que es a través de los medios de comunicación como se crean los estados de opinión que luego inciden de forma directa en la visión que la ciudadanía tiene de la Justicia”.

${ }_{60} \mathrm{Al}$ respecto puede consultarse el estudio realizado por TOHARIA, José Juan. Opinión pública y justicia. La imagen de la justicia en la sociedad española, Madrid: Consejo General del Poder Judicial, 2001, p. 84 y ss., quien sostiene que 
ido arrojando peores resultados de valoración, conceptuando a la justicia como una institución incomprensible para la sociedad.

Esta circunstancia invita a proponer un cambio en la política de comunicación que no se ciña exclusivamente a la trasmisión de la información judicial por todas las vías de comunicación posible. Se trata, en consecuencia, de adoptar nuevos mecanismos de comunicación ${ }^{61}$, desde una perspectiva más pedagógica, con la finalidad de acercar el funcionamiento del sistema judicial, las labores que desempeñan los jueces y la interpretación de las leyes, desde edades más tempranas.

En este sentido, las Fuerzas y Cuerpos de Seguridad llevan años desarrollando diversas campañas de comunicación basadas en conceptos muy claros y didácticos, con las que pretenden acercar la institución a la ciudadanía y reforzar el compromiso que adquieren con aquella. Esta misma pretensión podría ser adoptada por los gabinetes de comunicación ${ }^{62}$ mediante la elaboración de campañas visuales de corta duración en la que la Administración de Justicia, a través de un lenguaje claro y sencillo, pueda acercarse a la ciudadanía, poniendo especial énfasis en aquellos aspectos que puedan reforzar y potenciar su imagen. Así no solo se lograría dar un paso más en la metodología informativa que, hasta el momento, han utilizado las oficinas de prensa, sino también establecer un contacto mucho más directo con los ciudadanos mediante la difusión de mensajes con un vocabulario menos técnico y especializado dirigido a un público general.

la evaluación negativa no se debe a la percepción de un progresivo empeoramiento actual de la Justicia, sino a la gradual toma de conciencia de la mala situación global y de fondo de esta. El autor señala que no se trata de que los españoles piensen que desde los años 90 la Justicia haya ido continuamente a peor, sino que a medida que se ha extendido el conocimiento y familiarización con su situación real se ha ido generalizando la conciencia de sus deficiencias. No es, pues, en definitiva, la realidad la que ha empeorado: es la percepción de esa mala realidad la que se ha concretado y extendido.

${ }^{61}$ GARCÍA MOLINA, Pablo. Medios de comunicación y juicios paralelos. En: ÁLVAREZ ALARCÓN, Arturo; GARCÍA MOLINA, Pablo (Dirs.). Tendencias actuales del Derecho Procesal, Granada: Comares, 2019, p. 50-53.

${ }_{62}$ Sobre esta cuestión resulta interesante la propuesta realizada por RAMÍREZ ORTIZ, José Luis. La justicia penal en la sociedad digital. Teoría y derecho: revista de pensamiento jurídico, Valencia, n. 24, p. 62 y 63, 2018. 
En la realización de este nuevo reto el empleo de un lenguaje claro y sencillo desempeñará un papel fundamental para la consecución del objeto pretendido, ya que, entre otras muchas razones, la incomprensión que padece nuestro sistema de justicia radica en la utilización de términos técnicos, propios del ámbito profesional, que no adquieren la debida comprensión por el ciudadano medio. Esta circunstancia no obsta para que el empleo del lenguaje técnico se siga utilizando por los profesionales del derecho, pero si es necesario que, de cara a lograr una mayor comprensión por parte de la ciudadanía, se emplee un lenguaje más sencillo y cotidiano, en lo que respecta al ámbito comunicacional, que logre llegar a un mayor número de ciudadanos.

Por último, la consecución de estas perspectivas de futuro no será posible sin la dotación de los recursos humanos y materiales suficientes para todas las oficinas de prensa que integran el engranaje informativo del Poder Judicial.

Por supuesto, esta dotación debe reforzarse de la forma más igualitaria posible teniendo en cuenta las necesidades individuales de cada oficina y la circunscripción territorial en la cual se encuentra adscrita. En relación con lo dicho, Orenes Ruiz ${ }^{63}$ sostiene que las exigencias de personal se van a ver necesariamente incrementadas en aquellos Tribunales Superiores de Justicia cuya circunscripción se extienda al territorio de varias provincias. Para estos supuestos compartimos la propuesta que realiza el citado autor al sostener que el gabinete de comunicación debe contar con delegados en las distintas Audiencias Provinciales o, al menos, en aquellas que tengan una significativa carga de trabajo.

La implementación de esta propuesta facilitaría la labor informativa de la oficina de prensa, mejorando su cobertura informativa a través de la distribución equitativa del trabajo, lo que permitiría contar con un mayor número de profesionales encargados de llevar a cabo las funciones informativas orientadas a la consecución de los objetivos pretendidos.

Es ineludible, en cuanto a la profesionalización de las oficinas de prensa, hacer una breve mención a la formación en materia judicial que deben de adquirir las personas que trabajan en las mismas, ya que no

63 Siguiendo a ORENES RUIZ, Juan Carlos. Libertad de información y proceso penal. Los limites, Cizur Menor: Aranzadi, 2008, p. 107. 
solo deben tener conocimientos suficientes en materia periodística, sino que deben tener, a su vez, una adecuada formación de la terminología jurídica que les permita ser rigurosos en el desempeño de su labor para transmitir la información de manera objetiva y veraz.

Acorde a lo establecido compartimos el criterio de Ronda Iglesias cuando dice que "la especialización es más acuciante en el campo del periodismo de tribunales y que el rigor informativo resulta imprescindible, por los errores que pueden generar en daños muy superiores a los que se producen en otras esferas" ${ }^{64}$.

\section{Conclusiones}

Al comienzo de este estudio, planteábamos una serie de cuestiones en las que, si bien afirmamos que la labor informativa desempeñada por los medios de comunicación es necesaria para que el principio de publicidad procesal adquiera, a través de la denominada publicidad mediata, la proyección y virtualidad requerida, la falta de concordancia en los intereses y finalidades de la Administración de Justicia (basados en reforzar su imagen, aumentando la confianza de los ciudadanos en el sistema judicial) y de los medios de comunicación (orientados a lograr una mayor rentabilidad económica e influencia social) originan que la justicia mediática sea el efecto adverso del derecho a la información en el escenario judicial de la publicidad del proceso.

Esta circunstancia se manifiesta en la inversión que el principio de publicidad ha experimentado, en virtud del alcance mediático

64 Afirmación realizada por RONDA IGLESIAS, Javier. La especialización del periodismo judicial. Revista Latina de Comunicación Social, Tenerife, n. 39, 2001. Disponible en: https://www.redalyc.org/pdf/819/81939407.pdf. Acceso en: 09/07/2020. El autor añade en su artículo el siguiente ejemplo: confundir en una noticia la denominación del material con el que se ha fabricado un puente puede molestar al ingeniero encargado de la obra y poco más. Pero, el perjuicio personal es mucho mayor si por error se atribuye a alguien la comisión de un hecho delictivo o se le implica en un acontecimiento deleznable y se da como noticia por la radio, prensa y televisión. Puede asegurarse que, en el ámbito de los tribunales, el periodista trabaja con material sensible, lo que hace más necesario y exigible el rigor, la exactitud y la profesionalidad. 
y la dimensión social adquirida por el asunto judicial, ya que lo que originariamente era un derecho del justiciable, en la actualidad se puede convertir, eventualmente, en una rémora e influir de forma negativa en el desarrollo del debido proceso, cuya influencia puede repercutir, notablemente, en el estigma social del sujeto investigado.

Por ello, las oficinas de comunicación de la Administración de Justicia juegan un papel fundamental en el correcto y adecuado desempeño de la labor comunicacional, no solo por ser la fuente directa de una información objetiva, veraz y neutral, sino por configurarse, en la actualidad, como un recurso resolutivo con la capacidad de mitigar, en la medida de lo posible, los lances derivados del inapropiado ejercicio de las libertades informativas originarias de los juicios paralelos. Se trata, en consecuencia, de invertir la tendencia mediática y pseudojurídica derivada de la formación de los procesos mediáticos, mediante la consecución de nuevos retos y nuevas políticas de comunicación que realcen la imagen de la Administración de Justicia, logrando un aumento de la confianza de la ciudadanía en la institución. Para la consecución de tal fin, será necesario adoptar nuevas políticas de comunicación dirigidas al ciudadano medio a través del empleo de un lenguaje accesible, sin olvidar, en ningún caso, la apuesta por la comunicación directa que informe sobre la realidad procesal, salvaguardando las garantías que le son propias al principio de publicidad y evitando, así, la publicación del proceso.

\section{Bibliografía}

AMARILLO VOZMEDIANO, María de la Fe. Juicios paralelos y derechos del investigado y el encausado. La ley penal: revista de derecho penal, procesal y penitenciario, n. 142, p. 1-9, 2020.

ASENCIO MELLADO, Jose María. El proceso penal con todas las garantías. Revista Ius et veritas, Lima, n. 33, p. 235-247, 2006.

BUENO DE MATA, Federico. El principio de publicidad procesal ante la tecnología: juicios mediáticos, redes sociales y big data. En: RODRÍGUEZ GARCÍA, Nicolás; CARRIZO GONZÁLEZ-CASTELL, Adán; LETURIA INFANTE, Francisco Javier. (Dirs.). Justicia penal pública y medios de comunicación, Valencia: Tirant lo Blanch, 2018, p. 475-493. 
CAMARA NERY, Arianne. Considerações sobre o papel da mídia no processo penal. Trabalho de fim de curso - Pontifícia Universidade Católica Do Rio de Janeiro, Rio de Janeiro, 2010. https://doi.org/10.17771/PUCRio.acad.16733.

CAMARENA ALIAGA, Gerson W. Medios de comunicación y poder judicial. Tratamiento penal y procesal frente a los juicios paralelos. Cizur Menor: Aranzadi, 2018.

CARRETERO SAN JUAN, Maite; CORTÉS BECHIARELLI, Emilio. Juicios paralelos: el conflicto entre el poder judicial y los medios de comunicación en el proceso penal. Diario La Ley, n. 8902, p. 1-18, 2017.

CARRILLO, Marc. Derechos fundamentales y poder judicial en la sentencia de la manada. Teoría y derecho: revista de pensamiento jurídico, Valencia, n. 24, p. 64-91, 2018.

CORTÉS BECHIARELLI, Emilio. Juicios paralelos y derechos fundamentales del justiciable. Anuario de la Facultad de Derecho. Universidad de Extremadura, Cáceres, n. XXI, p. 123-151, 2003.

COUTURE, Eduardo J. Fundamentos del Derecho Procesal Civil, Buenos Aires: Depalma, 1990.

DEL RIEGO, Carmen. Frente a los juicios paralelos, información y rigor. Cuadernos de periodistas: revista de la Asociación de la Prensa de Madrid, n. 39, p.42-53, 2019. Disponible en: <http://www.cuadernosdeperiodistas.com/media/2020/02/42_ 53-Carmen-del-Riego-1.pdf>. Acceso en: 17 nov.2020.

DROGUETT GONZÁLEZ, Carmen; WALKER SILVA, Nathalie. El derecho a ser informado sobre los asuntos de interés público: defensa de los juicios paralelos en Chile: Problemas y soluciones. Revista Chilena de Derecho, Chile, Vol. 47, n. 1, p. 25-48, 2020. https://doi.org/10.4067/s0718-34372020000100033.

FERNÁNDEZ GARCÍA, Emilio. Juicios paralelos, imparcialidad de los tribunales y opinión pública: repercusiones en la vida política y en las resoluciones judiciales. Teoría y derecho: revista de pensamiento jurídico, Valencia, n. 24, p. 211-219, 2018.

FERNÁNDEZ MARTÍNEZ, Juan Manuel. El derecho a la libertad de expresión del juez, límites en consideración a su "status de especial sujeción” y en relación con las garantías procesales y derechos objeto de protección respecto a los intervinientes en el proceso. Los gabinetes de comunicación y su papel como cauce institucional de información. En: FRESNEDA PLAZA, Felipe (Dir.), Justicia y Medios de Comunicación, Cuadernos de Derecho Judicial, Madrid: Consejo General del Poder Judicial, n. 16, 2006, p. 137- 216. 
GARCÍA ARÁN, Mercedes. Libertad de información y procesos penales en curso. Teoría y derecho: revista de pensamiento jurídico, Valencia, n. 24, p.14-32, 2018.

GARCÍA MOLINA, Pablo. Medios de comunicación y juicios paralelos. En: ÁLVAREZ ALARCÓN, Arturo; GARCÍA MOLINA, Pablo (Dirs.). Tendencias actuales del Derecho Procesal, Granada: Comares, 2019, p. 47-59.

GUZMÁN FLUJA, Vicente Carlos. Juicios paralelos en las redes sociales y proceso penal. IDP: revista de internet, derecho y política. n. 27, p. 52-56, 2018. https://doi. org/10.7238/idp.v0i27.3148.

HUERTAS MARTÍN, Isabel. Proceso penal y comunicación en el siglo XXI: el inevitable juicio paralelo, el prescindible juicio paralelo show. En: RODRÍGUEZ GARCÍA, Nicolás; CARRIZO GONZÁLEZ-CASTELL, Adán; LETURIA INFANTE, Francisco Javier (Dirs.) Justicia penal pública y medios de comunicación, Valencia: Tirant lo Blanch, 2018, p. 405-455.

LATORRE LATORRE, Virgilio. Función jurisdiccional y juicios paralelos, Madrid: Civitas, 2002.

LAZZARI DA SILVEIRA, Felipe. Mídia, medo e controle: Ensaio sobre o papel da mídia na dinãmica do recrudescimento do sistema penal. Cadernos de Comunicação, v.20, n.2, p.1-21, 2016. https://doi.org/10.5902/2316882X17976.

LETURIA INFANTE, Francisco Javier. La publicidad procesal y el derecho a la información frente a asuntos judiciales. Análisis general realizado desde la doctrina y jurisprudencia española. Revista chilena de derecho, Chile, v. 45, n. 3, p. 647-673, 2018. http://doi.org/10.4067/S0718-34372018000300647.

LETURIA INFANTE, Francisco Javier. La problemática de los juicios paralelos en la jurisprudencia y doctrina española. Revista Ius et Praxis, Chile, n. 2, p. 21-50, 2017. https://doi.org/10.4067/s0718-00122017000200021.

LÓPEZ GUERRA, Luis. Juicios paralelos, presunción de inocencia y jurisprudencia del Tribunal Europeo de Derechos Humanos. Teoría y derecho: revista de pensamiento jurídico, Valencia, n. 24, p. 34-49, 2018.

MONTERO AROCA, Juan, con GÓMEZ COLOMER, Juan Luis, MONTÓN REDONDO, Alberto y BARONA VILAR, Silvia. Derecho jurisdiccional I, Valencia: Tirant lo Blanch, 2008.

NIEVA FENOLL, Jordi. Los juicios paralelos: su complejo encaje constitucional. En: MIR PUIG, Santiago; CORCOY BIDASOLO, Mirentxu (Dir.), Protección penal de la libertad de expresión e información: Una interpretación constitucional, Valencia: Tirant lo Blanch, 2012, p. 219-252. 
ORENES RUIZ, Juan Carlos. Libertad de información y proceso penal. Los limites, Cizur Menor: Aranzadi, 2008.

ORENES RUIZ, Juan Carlos. Juicios paralelos y prensa digital. En: GAVARA DE CARA, Juan Carlos, DE MIGUEL BÁRCENA, Josu y RAGONE, Sabrina (Dir./ Coord.). El control de los cibermedios. Barcelona: Bosch Editor, 2014, p. 91-106. https://doi.org/10.2307/j.ctvrzgzvv.7.

OTERO GONZALEZ, María del Pilar. Protección penal del secreto sumarial y juicios paralelos, Madrid: Centro de estudios Ramón Areces, 1999.

PEDRAZ PENALVA, Ernesto. Publicidad y derecho al debido proceso. Publicidad y derecho de acceso a la información contenida en los ficheros de datos jurisdiccionales. En: GUTIÉRREZ-ALVIZ CONRADI, Faustino. (Dir.), Criminalidad organizada ante la justicia, Sevilla: Universidad de Sevilla, 1996, p. 157-190.

PERAL PARRADO, María. La presunción de inocencia y la defensa efectiva: la responsabilidad de los medios y de los periodistas. Revista del Consejo General de la Abogacía Española, Madrid, n.111, p. 28-29, 2018.

QUINTERO OLIVARES, Gonzalo. La justicia penal en España, Elcano: Aranzadi, 1998.

RAMÍREZ ORTIZ, José Luis. La justicia penal en la sociedad digital. Teoría y derecho: revista de pensamiento jurídico, Valencia, n. 24, p. 50-63, 2018.

RENEDO ARENAL, María Amparo. Problemas del imputado en el proceso penal, Madrid: Editorial universitaria Ramón Areces, 2007.

RODRÍGUEZ BAHAMONDE, Rosa. El secreto del sumario y la libertad de información en el proceso penal, Madrid: Dykinson, 1999.

RODRÍGUEZ RAMOS, Luis. La verdad y las verdades en el proceso penal. ¿Hacia una justicia dependiente de los medios de comunicación?. La Ley: Revista jurídica española de doctrina, jurisprudencia y bibliografía, Madrid, n. 5, p. 1506 - 1512, 2002.

RONDA IGLESIAS, Javier. La especialización del periodismo judicial. Revista Latina de Comunicación Social, Tenerife, n. 39, 2001. Disponible en: https://www. redalyc.org/pdf/819/81939407.pdf. Acceso en: 09/07/2020.

SAN MIGUEL CASO, Cristina. La cobertura mediática en el sistema de la estrategia de la defensa penal. En: RODRÍGUEZ GARCÍA, Nicolás; CARRIZO GONZÁLEZ-CASTELL, Adán; LETURIA INFANTE, Francisco Javier (Dirs.) Justicia penal pública y medios de comunicación, Valencia: Tirant lo Blanch, 2018, p. 359-377. 
TOHARIA, José Juan. Opinión pública y justicia. La imagen de la justicia en la sociedad española, Madrid: Consejo General del Poder Judicial, 2001.

WACH, Adolf. Conferencias sobre la ordenanza procesal civil alemana (Trad. E. Krotoschin), Buenos Aires: Ediciones Jurídicas Europa-América, 1958.

WYNESS MILLAR, Robert. Los principios formativos del procedimiento civil (Trad. C. Grossmann), Buenos Aires: Ediar S.A. Editores, 1945.

ZURITA PINILLA, Agustín. Oficinas de prensa en la Administración de justicia. Revista del Poder Judicial, La Laguna, n. extra 13, p. 231-240, 1990.

\section{Informações adicionais e declarações dos autores (integridade científica)}

Declaração de conflito de interesses (conflict of interest declaration): a autora confirma que não há conflitos de interesse na realização das pesquisas expostas e na redação deste artigo.

Declaração de autoria e especificação das contribuições (declaration of authorship): todas e somente as pessoas que atendem os requisitos de autoria deste artigo estão listadas como autores; todos os coautores se responsabilizam integralmente por este trabalho em sua totalidade.

Declaração de ineditismo e originalidade (declaration of originality): a autora assegura que o texto aqui publicado não foi divulgado anteriormente em outro meio e que futura republicação somente se realizará com a indicação expressa da referência desta publicação original; também atesta que não há plágio de terceiros ou autoplágio. 


\section{Dados do processo editorial}

(http://www.ibraspp.com.br/revista/index.php/RBDPP/about/editorialPolicies)

- Recebido em: 10/07/2020

Equipe editorial envolvida

- Controle preliminar e verificação de plágio: 25/07/2020

- Avaliação 1: 27/07/2020

- Editor-chefe: 1 (VGV)

- Revisores: 2

- Avaliação 2: 05/08/2020

- Decisão editorial preliminar: 04/10/2020

- Deslocamento ao V7N1 e aviso autora: 04/10/2020

- Retorno rodada de correções: 20/11/2020

- Decisão editorial final: 02/12/2020

\section{COMO CITAR ESTE ARTIGO:}

SAN MIGUEL CASO, Cristina. Los juicios paralelos en España:

El efecto adverso de la libertad de información en la publicidad mediata. Revista Brasileira de Direito Processual Penal, Porto Alegre, vol. 7, n. 1, p. 443-474, jan./abr. 2021.

https://doi.org/10.22197/rbdpp.v7i1.419

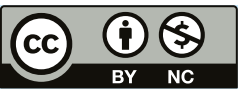

Esta obra está licenciada com uma Licença Creative Commons Atribuição-NãoComercial 4.0 Internacional. 